\title{
Epidemiological and clinical aspects of respiratory pathologies during pregnancy and puerperality
}

\author{
Kouamé Arthur Didier ${ }^{1 *}$, Diomandé Fatoumata Alice1, Kakou Charles ${ }^{1}$, Alla Christian ${ }^{1}$, \\ Koffi Soh Victor', Boko Alexandre ${ }^{2}$, Kouakou Firmin ${ }^{1}$
}

${ }^{1}$ Department of Obstetrics and Gynecology, ${ }^{2}$ Department of Pneumology, University Hospital of Cocody, Abidjan, Cote D'ivoire

Received: 26 January 2018

Accepted: 29 January 2018

*Correspondence:

Dr. Kouamé Arthur Didier,

E-mail: arthur.kouame@mail.huji.ac.il

Copyright: (c) the author(s), publisher and licensee Medip Academy. This is an open-access article distributed under the terms of the Creative Commons Attribution Non-Commercial License, which permits unrestricted non-commercial use, distribution, and reproduction in any medium, provided the original work is properly cited.

\begin{abstract}
Background: The purpose of this study was to describe the characteristics of respiratory pathologies during pregnancy and postpartum.

Methods: This was a case-control study over a 7-year period from January 2008 to December 2014 at CHU de COCODY. We compiled 86 cases of the PPH department hospitalized patients for pulmonary disease during pregnancy and for postpartum up to 42 days after delivery. The control samples were represented by those hospitalized in Obstetrics for a non-respiratory general condition during the same gravido puerperal period.

Results: The age group of 20-29 years was the most affected in both groups with extremes ranging from 16 to 40 years $(p=0.827)$. Respiratory pathology was common among housewives or unemployed women $(p=0,001)$. Pauciparous and multiparous were the most affected $(\mathrm{p}=0.020)$. They had a medical history in $55.8 \%$ of cases versus $22.8 \%$ in controls $(\mathrm{p}=0.001)$. Positive HIV serology was also found $(\mathrm{p}=0.001)$ and was most often passive tobacco related $(\mathrm{p}=0.015)$. Respiratory pathology was progressive in $72.9 \%$ in cases $v$ s $8.9 \%(\mathrm{p}=0.001)$ with dyspnoea as the main sign $(58 \%)$. Tuberculosis $(29.70 \%)$ was the most common respiratory disease. Maternal complications accounted for $48.1 \%$ of PPH vs $25.6 \%(\mathrm{p}=0.001)$ with maternal mortality of $11.6 \%(\mathrm{p}=0.001)$. As for foetal prognosis, $25.6 \%$ of foetal complications were noted in patients admitted to PPH versus $48.1 \%(\mathrm{p}=0.001)$.

Conclusions: Respiratory disease during the gravido puerperal period is severe with significant maternal repercussion.
\end{abstract}

Keywords: Pregnancy, Postpartum, Respiratory diseases

\section{INTRODUCTION}

WHO estimates that 303,000 women died in 2015 , including 302,000 in developing countries. ${ }^{1}$ Respiratory disease, which is often less pointed at, is still the thirdhighest cause of mortality in the world's female population in middle-income countries, with tuberculosis among the top five causes of death among women of reproductive age in developing countries. ${ }^{2}$
During pregnancy, women are exposed to nasal congestion, hyperventilation and the diaphragm moves up. These lead to changes in respiratory capacity for ventilation. Furthermore, respiratory responses are greatly affected by the stage of labour with a dramatic increase in oxygen consumption at the moment of parturition. Indeed, physiological changes of the respiratory system brought about by pregnancy weaken the said system, which associated with pathological 
illness, significantly compromise the respiratory function with serious consequences for the mother-child couple. ${ }^{3}$ For example, $8-12 \%$ patients will experience Bronchial asthma during pregnacy. There will be an exacerbation for $12.6 \%$ of them; and $6 \%$ may require hospital admission which occurs mostly around end of the second trimester and the early third trimester. However, clinical presentation and management of pulmonary diseases in pregnant women are almost similar to non-pregnant one according to the literature. ${ }^{3}$ The general goal of our study was to describe the characteristics of respiratory pathologies during pregnancy and postpartum.

\section{METHODS}

This was a case-control study that took place at CHU de Cocody over a 7-year period from January 2008 to December 2014. The Cases were represented by pregnant or newly delivered women hospitalized at the PPH for respiratory disease. And the pregnant or delivered women hospitalized in Obstetrics for a non-respiratory general pathology constituted the controls. Pregnancies were unique and single deliveries were included in the study.

\section{Inclusion criteria}

With regard to inclusion criteria, we retained the following as:

- Cases: patients hospitalized at PPH for a respiratory disease that occurred during pregnancy or within 42 days after delivery (about 2 months).

- Control Sample: those hospitalized in Obstetrics for a non-respiratory general condition during the same gravido puerperal period.

\section{Exclusion criteria}

The criteria for non-inclusion were:

\section{For cases}

- any patient hospitalized with PPH outside the gravido puerperiality period.

- $\quad$ any patient with pulmonary disease during pregnancy or post partum up to 42 after delivery but who have not been hospitalized at PPH

\section{For the control sample}

- all patients hospitalized in obstetrics for a pathology specifically related to gravido puerperal and / or its complication, and the files where diagnoses were not specified.

- any patient not hospitalized in Obstetrics for a nonrespiratory general condition during the same gravido puerperal period.

The parameters studied were: socio-demographic characteristics, type of respiratory pathology, medical history, HIV status, smoking status, maternal complications, maternal deaths, fetal complications and fetal deaths.

\section{Statistical analysis}

Data analysis was conducted using the Epi-info software with an alpha threshold of materiality less than 0.05 .

\section{RESULTS}

\section{Sociodemographic characteristics, pregnancy monitoring and history}

Table 1: Epidemiological profile, pregnancy monitoring and history.

\begin{tabular}{|c|c|c|c|c|c|}
\hline \multirow{2}{*}{$\begin{array}{l}\text { Parametres } \\
(\text { OR, IC 95\%) }\end{array}$} & \multicolumn{2}{|c|}{ Cases } & \multicolumn{2}{|c|}{ Controls } & \multirow{2}{*}{$\begin{array}{l}\mathbf{P} \\
\text { value }\end{array}$} \\
\hline & $\mathbf{N}$ & $\%$ & $\mathbf{n}$ & $\%$ & \\
\hline Age in year & & & & & 0.827 \\
\hline$\leq 18$ years & 7 & 8.14 & 5 & 6.33 & \\
\hline $19-29$ years & 53 & 61.63 & 52 & 65.82 & \\
\hline $30-40$ years & 26 & 30.23 & 22 & 27.85 & \\
\hline Profession & & & & & 0.001 \\
\hline Employed & 14 & 17.7 & 5 & 5.8 & \\
\hline Informal Sector & 38 & 48.1 & 27 & 31.4 & \\
\hline Pupil/student & 9 & 11.4 & 7 & $8.1 \%$ & \\
\hline $\begin{array}{l}\text { Housewife/ } \\
\text { unemployed }\end{array}$ & 18 & 22.8 & 47 & 54.6 & \\
\hline Parity & & & & & 0.020 \\
\hline $\begin{array}{l}0-1 \text { (Nullipare, } \\
\text { primipare) }\end{array}$ & 38 & 44.2 & 54 & 68.4 & \\
\hline $\begin{array}{l}2+\text { (Paucipare, } \\
\text { multipare) }\end{array}$ & 48 & 55.8 & 25 & 31.6 & \\
\hline Place of CPN & & & & & $<0.001$ \\
\hline None & 5 & 5.8 & 22 & 27.8 & \\
\hline $\mathrm{CHU}$ & 0 & 0.0 & 7 & 8.9 & \\
\hline HG/CHR & 0 & 0.0 & 2 & 2.5 & \\
\hline Maternity & 70 & 81.4 & 39 & 49.4 & \\
\hline Clinic & 11 & 12.8 & 9 & 11.4 & \\
\hline Quarter of statement & & & & & 0.031 \\
\hline None & 6 & 7.0 & 22 & 27.8 & \\
\hline $1^{\text {st }}$ quarter & 24 & 27.9 & 23 & 29.1 & \\
\hline $2^{\text {nd }}$ quarter & 56 & 65.1 & 33 & 41.8 & \\
\hline $3^{\text {rd }}$ quarter & 0 & 0.0 & 1 & 1.3 & \\
\hline Prenatal review & & & & & 0.001 \\
\hline Complete & 12 & 14.0 & 10 & 12.7 & \\
\hline Incomplete & 42 & 48.8 & 18 & 22.8 & \\
\hline None & 32 & 37.2 & 51 & 64.6 & \\
\hline $\begin{array}{l}\text { Preexisting pathologie } \\
(\mathrm{OR}=4.281 \text {; IC } 95 \%:\end{array}$ & .177 & $8.419)$ & & & 0.001 \\
\hline Yes & 48 & 55.8 & 18 & 22.8 & \\
\hline No & 38 & 44.2 & 61 & 77.2 & \\
\hline HIV status $(\mathrm{OR}=15.0$ & $2 ; \mathrm{IC}$ & $95 \%: 4$ & $371-5$ & $1.555)$ & 0.001 \\
\hline Negative & 54 & 62.8 & 76 & 96.2 & \\
\hline Positive & 32 & 37.2 & 3 & 3.8 & \\
\hline Passive smoking (3.38 & $3 ; 1$. & $77-9.72$ & & & 0.015 \\
\hline No & 70 & 81.4 & 74 & 93.7 & \\
\hline Yes & 16 & 18.6 & 5 & 6.3 & \\
\hline Total & 86 & 100 & 79 & 100 & \\
\hline
\end{tabular}


The 19-29 age group was the most affected in both groups. Housewives or unemployed women were significantly admitted for respiratory condition. Pauciparas and multiparas were the most concerned. Prenatal follow-up in the peripheral maternities and clinics, as well as the first prenatal consultation in the 2nd quarter were associated significantly with respiratory condition.

Antenatal assessment was incomplete in $48.8 \%$ in cases vs $22.8 \%$. The existence of pre-existing pathologies was significantly associated with respiratory impairment. HIV serology in $37.2 \%$ was positive in cases vs $3.8 \%$. Cases in $18.6 \%$ were passive smoking vs. $6.3 \%$.

\section{Clinical study}

Pregnant women accounted for $64 \%(n=55 / 128)$ of the cases, these pregnant were admitted to the service of PPH of the CHU de Cocody most often in the 2nd and 3rd trimester of pregnancy $(\mathrm{p}=0.079)$. These patients were admitted mainly for dyspnoea (58\%), wet cough (14\%), and chest pain $(13 \%)$. Of the cases, 36\% ( $n=31 / 37)$ gave birth versus $7.6 \%$ in the control group $(p=0.001)$. Tuberculosis (29.7\%), acute bacterial pleuropneumopathy $(9.7 \%)$ and asthma $(6 \%)$ were the main diagnoses retained.

\section{Maternal-foetal prognosis}

\section{Maternal prognosis}

Maternal complications were $24.4 \%$ in the cases versus $6.3 \%$ in the controls $(\mathrm{OR}=4.782$; IC 95\%=1.706-13.402; $\mathrm{p}=0.001)$. Maternal complications were represented by cardiovascular complications in $4.2 \%$ of cases $(n=7)$, followed by respiratory distress in $2.4 \%$ of cases $(n=4)$, consciousness disorders in $2.4 \%$ cases $(n=4)$, medicinal hepatitis in $1.8 \%$ of cases $(n=3)$, severe anaemia in $1.8 \%$ of cases $(n=3)$ and sepsis in $1.2 \%$ of cases $(n=2)$. We had one case $(0.9 \%)$ of kidney failure, thrombocytopenia, and metabolic disorder (hypoglycaemia).

Patients discharged against medical advice in $23.2 \%$ $(n=20)$ in cases versus $5.1 \%(n=4)$ in controls $(p=0.001)$. The transfer rate in another service was almost the same in the two study populations with $7 \%(n=6)$ in the cases and $7.6 \%$ in the controls. There was significantly less outcome after favourable outcome $(\mathrm{p}<0.001)$ in the cases $(58.1 \% ; n=50)$ than in the controls $(87.3 \%, n=69)$

Maternal deaths accounted for $11.6 \%(10 / 86)$ of the cases versus no deaths in the controls $(\mathrm{p}=0.001)$.

\section{Foetal prognosis}

Foetal complications accounted for $25.6 \%$ of cases vs. $48.1 \%$ of controls with statistically significant difference $(\mathrm{p}=0.002)$ with 10 in utero foetal deaths observed only in controls.
Foetal harm was most marked by threats of abortion or childbirth (13.8\%), pre and post partum death $(9 \%) ; 5$ spontaneous abortions and 8 premature births observed either $7.8 \%$ followed by premature rupture of the membranes $(2.4 \%)$ and 3 cases of IUGR (1.8\%).

Table 2: Foetal complications.

\begin{tabular}{|lll|}
\hline Foetal Complications & $\begin{array}{l}\text { Number } \\
(\mathrm{n}=165)\end{array}$ & Percentage \\
\hline Threat of premature delivery & 10 & 6 \\
\hline Premature delivery & 8 & 4.8 \\
\hline Neonatal death & 5 & 3 \\
\hline Wrong APGAR & 2 & 1.2 \\
\hline Threat of abortion & 13 & 7.8 \\
\hline $\begin{array}{l}\text { Spontaneous abortion } \\
\text { In utero foetal death }\end{array}$ & 5 & 3 \\
\hline $\begin{array}{l}\text { Intrauterine growth } \\
\text { retardation }\end{array}$ & 10 & 6 \\
\hline $\begin{array}{l}\text { Premature rupture of } \\
\text { membranes }\end{array}$ & 3 & 1.8 \\
\hline
\end{tabular}

\section{DISCUSSION}

Pregnancy follow-up and socio-demographic characteristics

The most affected age group is between 19-29 years old, i.e. $63.64 \%$ of the total number, with an average of 27.39 years. It corresponds to the period of full genital activity in Africa. Indeed, the fact that the peak of fertility of Ivorian women in reproductive activity is between 25-29 years. ${ }^{4}$ Data from the African or even European literature show an average age of around 27 years in the case of pulmonary pathology and pregnancy. ${ }^{5,6}$

Most of the patients came from the communes of Cocody $(31.5 \%)$ and 3 popular communes of Abidjan namely Abobo (24.2\%), Adjamé (12.1\%) and Yopougon (12.1\%); this is explained by the fact that the CHU de Cocody, place of our study is the first resort of these communities because of the geographical proximity. As for the aforementioned communal trio, it is inhabited by families with modest incomes even disadvantaged, living in promiscuity, poor hygiene conditions with lack of adequate sanitary infrastructure, and saturation of urban roads by a dilapidated and intense automobile traffic. Some authors draw attention to the respiratory risk of air pollution in southern countries. ${ }^{7,8}$

Thus, this study revealed that housewives and the unemployed were significantly eligible for respiratory diseases $(p=0.001)$. In fact, the health of these women is subject to increased risks, mainly because of their social and economic roles, which expose them to a greater number of environmental hazards. Because they are those who prepare food for the home, these women in the developing world are often exposed to very high levels of smoke from cooking stoves, smoke from indoor fireplaces burning wood and/or charcoal weakening the 
respiratory tract. Present results are almost similar to that of Ago who found $41.3 \%$ of housewives. ${ }^{9}$

Patients admitted to PPH had declared their pregnancy in the 2 nd quarter in $65.1 \%$ of the cases against $41.8 \%$ in the controls $(\mathrm{p}=0.031)$. This finding of late consultation in case of pregnancy is also made by several African authors such as Koffi NM and Mafuta who found respectively $60.8 \%$ and $59.8 \%$ of late consultation. ${ }^{10,11}$

Concerning the prenatal assessment, $48.8 \%$ of the patients with respiratory diseases had an incomplete report compared to $22.8 \%$ in the controls with a statistically significant difference of 0.001 . Poor prenatal care is an almost ineffective factor in maternal morbidity. ${ }^{12,13}$ The national prenatal survey in France also highlighted the link between social disparities and poor monitoring of pregnancy. It further noted that women who have declared their pregnancy outside the statutory period are characterized by the fact that they live alone, and that resorting to a general practitioner to report pregnancy mainly concerns women without a profession and women living alone (30\% vs. $23 \%$ of those living in a couple). ${ }^{14}$

Similarly, the place of ANC was closely correlated with respiratory impairment $(p<0.001)$, in fact $81.4 \%$ of patients admitted to $\mathrm{PPH}$ benefited from ANC in peripheral maternity clinics versus $49.4 \%$ of controls. Peripheral maternity clinics rank at the first level of our health pyramid, there are often no doctors, let alone specialists, so ANCs are most often provided by midwives who do not have all the skills required to adequately take care of patients. Cisse in Senegal did the same. $^{15}$

\section{History and respiratory disease}

The main respiratory diseases identified in our study were tuberculosis $(29.7 \%)$ followed by acute pleuro bacterial pneumonia $(9.7 \%)$ and asthma $(6 \%)$ : main non-infectious pathology. Our results corroborate with those of authors among others Ago and Koffi in Côte d'Ivoire and Cissé in Dakar. ${ }^{8,15,16}$ The predominance of these pathologies can be explained by the fact that these are pathologies that are on the increase in our developing countries and occur willingly in debility ground. Thus, 55.8\% of patients hospitalized with PPH already had a medical history versus $22.8 \%$ among the control sample with a statistically significant difference. These antecedents were dominated by asthma and allergic ground (14.6\%), hemoglobinopathies $(6.10 \%)$ and tuberculosis contagion $(6.10 \%)$. The data in literature are unanimous as to the implication of these defects in the occurrence of respiratory pathologies.

Allergic inflammation is responsible for bronchial remodelling with definitive persistence of an obstruction, which if untreated and generates recurrence or worsening of attacks toward a severe acute asthma. ${ }^{17}$ As for sickle cell disease, its pulmonary complications are well known and common. Koffi, in a series of 45 sickle cell patients, reported $94 \%$ non tuberculosis pneumonia and $6 \%$ tuberculosis. $^{18}$

Resende also found a link between sickle cell disease in pregnant women and respiratory disease. ${ }^{19}$ Regarding tuberculosis contagion, the epidemiology and natural history of tuberculosis identify people close to patients with contagious tuberculosis as being most at risk of tuberculosis infection. This means family and communities reproducing conditions of promiscuity fairly similar to family promiscuity. ${ }^{20}$

In our series, the first immunosuppressive factor is the pregnancy state, in fact, pregnant women were mainly represented at $77.60 \%$, while the deliveries were $22.40 \%$. Touré et al had the same results. ${ }^{5,6}$ These pregnant women were admitted mainly in the $2^{\text {nd }}$ quarter $(40.60 \%)$ and in the $3^{\text {rd }}$ quarter $(50.80 \%)$ of the pregnancy. Lakhdar and Alonso have made the same observation. ${ }^{21,22}$ The peculiarity of our study is that $36 \%$ of births were due to $\mathrm{PPH}$ compared to $7.6 \%$ in the control sample with a statistically significant difference $(p<0.001)$. This shows that postpartum also remains a risk period for the mother.

In addition, HIV infection is a major factor for the outbreak of respiratory pathology. In fact, pulmonary condition is the first manifestation of AIDS, in more than $50 \%$ of cases. ${ }^{20}$ In this study, HIV seropositivity was significantly related to respiratory condition $(p<0.001)$. The study of Horo in the same department showed that HIV infection was associated with tuberculosis in $82.86 \%$, acute bacterial pneumonopathy in $77.22 \%$ and febrile pulmonary pneumopathies in $92.23 \% .^{23}$ Ouédraogo in Burkina Faso, noted that $92 \%$ of patients were infected with HIV1. ${ }^{24}$ Not surprisingly, HIV infection poses major challenges to efforts to reduce the high rate of pneumonia-related mortality in sub-Saharan Africa areas where HIV is endemic. ${ }^{25}$

Another and not the least factor, increasingly indicated with regard to susceptibility to respiratory pathologies is exposure to passive tobacco smoke. According to Jayet, passive smoking poses a much real threat to health nowadays. ${ }^{26}$ In Switzerland, for example, about 1,000 deaths per year are attributed to passive smoking, a quarter of which is due to chronic respiratory or oncology diseases. ${ }^{26} \mathrm{We}$ identified $18.6 \%$ of patients admitted to $\mathrm{PPH}$ exposed to passive smoking compared to $6.3 \%$ in $\mathrm{GO}(\mathrm{p}=0.015)$.

Regarding obstetrical history, literature identifies multiparity but increasingly pauciparity as a risk factor threatening maternal health. ${ }^{27-29}$ We recorded a predominance of pauciparous and multiparas (parity $\geq 2$ ) with respiratory conditions with a statistically significant difference $(p=0.020)$. This once again demonstrates the importance of monitoring any pregnancy, as each 
pregnancy is potentially considered at risk and may be subject to complications.

\section{Clinical characteristics and maternal-foetal prognosis}

Dyspnoea (58\%) was the main reason for respiratory admission. AGO [9] also found this same pattern at a frequency of $49 \% .^{9}$ The dyspnoea is almost present during the woman because of the adaptation of the respiratory system to the gravidic state, $60 \%$ of pregnant women without pulmonary disease present a respiratory condition. ${ }^{30} \mathrm{~A}$ pathological state grafted on this ground further worsens the respiratory function. In addition, the other respiratory signs (cough, chest pain) that are often forerunners are neglected by the population and do not motivate early consultation, but in the face of respiratory condition, fear sets in.

The first quarter of symptom onset was mainly (52.9\%) in the first two quarters of pregnancy and $47.10 \%$ in the third quarter. It should also be noted that the onset of the disease was progressive in $72.9 \%$ of $\mathrm{PPH}$ and brutal in $91.1 \%$ with the control sample $(\mathrm{p}<0.001)$. that is the reason behind the mixed maternal-foetal repercussions observed. Indeed, the maternal prognosis was more severe in cases of respiratory disease. Our study shows that mothers admitted to PPH had $24.4 \%$ complications compared to $6.3 \%$ in controls $(p=0.002)$. Maternal mortality was $11.60 \%$ in PPH when no patient died in the GO group $(p<0.001)$. This reflects the severity of respiratory impairment with mothers, which is on the one hand related to late diagnosis due to insidious progression of the pathology and on the other hand to generated multi-visceral failure. The main complications found in our study were cardiovascular disease $(4.2 \%)$, respiratory distress $(2.4 \%)$ and coma $(2.4 \%)$. That is why the Iloki study in Brazzaville rightly identified respiratory pathologies as the second leading cause of death in women of childbearing age. ${ }^{31}$

The foetal prognosis, meanwhile, was less alarming in case of respiratory condition. $25.6 \%$ of foetal complications were found in PPH compared with $48.1 \%$ in controls with 10 in utero foetal deaths, found only in GO. Indeed, fever (61\%), which was the main nonrespiratory cause in our study, is a risk factor for foetal death. ${ }^{32}$ Other foetal complications were dominated by threats of abortion or childbirth $(13.8 \%)$, premature delivery (4.8\%), and neonatal death (3\%). The Ago study also concluded that there is a poor maternal-foetal prognosis in case of low respiratory pathology during pregnancy. ${ }^{9}$

\section{CONCLUSION}

Respiratory disease during the gravido puerperal period remains serious with significant maternal repercussions. Knowledge of identified associated factors will better prevent and manage respiratory pathology during pregnancy; and from there reduce the maternal mortality attached to it.

Funding: No funding sources

Conflict of interest: None declared

Ethical approval: The study was approved by the Institutional Ethics Committee

\section{REFERENCES}

1. WHO, UNICEF, UNEFPA. Trend in maternal mortality: 1990-2015. Executive Summary: 16 pages. Available at https://www.unicef.org/eapro/MMR_executive_sum mary_final_mid-res.pdf

2. Raghu S, Surya KP. Respiratory diseases in pregnancy. J Clin Sci Resp. 2015;4:149-58.

3. WHO. Global Health Estimates, Women's Health. Fact sheet No. 334-September 2013. Available at http://www.who.int/mediacentre/factsheets/fs334/en/

4. National Institute of Statistics. Demographic and health survey and with multiple indicators in Côte d'Ivoire;2011-2012:73. Available at http://ghdx.healthdata.org/record/c\%C3\%B4tedivoire-demographic-and-health-survey-2011-2012

5. Dolley P. Acute pulmonary oedema and pregnancy: descriptive study of 15 cases and review of literature. J Gynecol Obstet Biol Reprod. 2012;7(41):638-44.

6. Touré NO. Tuberculosis and pregnancy: about 11 cases in the Department of Pneumology CHU FANN. Rev Respir Dis. 2003:153-266.

7. Nejjari C, Filleul L, Tessier JF. Air pollution, a new respiratory risk for cities in the South Pollution, respiratory health and cities in the South. Int $\mathbf{J}$ Tuberculosis Lung Dis. 2003;7(3):223-31.

8. Ibrahima SY. Health and environmental vulnerability in underprivileged districts of Nouakchott (Mauritania), analysis of conditions of emergence and development of diseases in Sahelian urban environment. Environmental Rev. 2012;11:2.

9. Ago LP. Low respiratory diseases during pregnancy. Doctoral thesis in medicine. Universtity FHB of Cocody, Abidjan 2014: no 5754/14.

10. Koffi NM. The health book in the monitoring of pregnancy in Côte d'Ivoire- Medicine of Black Africa: 2000;47(4).

11. Mafuta EM. Determinants of late attendance at antenatal care services in Ecuador and Katanga health zones in the Democratic Republic of Congo. Annal Med Afr. 2011;4(4):845.

12. Benié BV. Prevalence and determinants of home deliveries in 2 precarious neighbourhoods of the municipality of Yopougon (Abidjan). Public Health. 2009;21:499-506.

13. Diakaridia. Relationship between prenatal consultation, future of pregnancy and delivery at CHU du Point G: study on1296 cases. PhD Thesis in Medicine 2009 Bamako.

14. Scheidegger S, Vilain A. Studies and results on social disparities and pregnancy surveillance. Fact 
sheet No. 552. 2007:2. Available at www.drees.solidarites-sante.gouv.fr /IMG/pdf/er552.pdf

15. Cissé CT. Tuberculosis and Pregnancy: Epidemiology and Prognosis at the CHU de Dakar Letter from the Gynaecologist No. 325. 2007:8-10. Available at www.refdoc.fr $>$ detailnotice

16. Koffi N. Profile of adult asthmatics followed in consultation in Africa in Abidjan. Medicine of Black Africa.2001;48 (11).

17. Guez S. Allergiques, take your background treatment for fear of aggravation. 2004. Available at www.allergique. Accessed on 14/06/15.

18. Koffi N. Aetiologies of low respiratory infections in major sickle cell disease of the black African. Med Black Afr. 2001;48(7).

19. Resende Cardoso PS, Lopes Pessoa de Aguiar RA, Viana MB. Clinical complications in pregnant women with sickle cell disease: prospective study of factors predicting maternal death or near miss. Rev Bras Hematol Hemoter. 2014 Jul-Aug;36(4):256-63.

20. Institute of Public Health France. Tuberculosis: treatment and prevention. Investigations to lead around a case of tuberculosis or recent tuberculosis infection. Available at invs.santepubliquefrance.fr. Accessed on 21/09/2016.

21. Lakhdar I. Pulmonary Tuberculosis and Pregnancy, Doctoral Thesis 1999-Faculty of Medicine and Pharmacy Toubkal University MOHAMMED V, Souissi-Rabat. Available at www.toubkal.imist.ma >handle

22. Alonso AM. Varicella pneumonia used during pregnancy after double counting in the 2nd quarter: value of seroprophylaxis. J Gynaecol Reprod Biol. 1999;28:838-41.

23. Horo K. Dynamics of respiratory pathology in a pneumology department in Black Africa in the context of HIV infection from 1998 to 2007. Rev Clin Pneumol. 2012;68:180-4.
24. Ouedraogo M, Thiombiano P. Morbi-mortality related to respiratory diseases in patients infected with HIV in Ouagadougou. Thesis of Medicine No. $022 / 2002$.

25. The International Union against Tuberculosis and Respiratory Diseases. Respiratory disease related to HIV-2016, consulted on November 02, 2016. Available at www.theunion.org

26. Jayet PY. Passive smoking and adult respiratory health: a real threat. Med Rev Switzerland. 2008;4:2494-9

27. Barry B. Maternal Mortality: causes and risk factors determined by verbal autopsy in the BAKEL Department. Cheick Anta Diop University of Dakar. 2008.

28. Ahbibi A. Maternal Mortality in Obstetric Resuscitation, Thesis 28-15-Faculty of Medicine and Pharmacy-MARRAKECH, page 14-15.

29. Gandzien PC. Maternal mortality at the TalangaiBrazaville Hospital Center. Med J Black Afr. 2005;52:657-60.

30. Ravaut C. Dyspnoea in the $3^{\text {rd }}$ quarter in pregnant women. DES general medicine course. Accesed on 11/07/2016 Availble http://slideplayer.fr/slide/10164423: 6 slides

31. Iloki LH, G'Bala MS, Kpekpede F, Ekoundzola JR. Maternal mortality in Brazzaville (1993-1994). J Gynaecol Obstet Reprod Biol. 1997;26(2):163-8.

32. Benedict G. Fever and pregnancy. J Gynaecol Obstet Reprod Biol. 2008;37:41-8.

Cite this article as: Didier KA, Alice DF, Charles K, Christian A, Victor KS, Alexandes B et al. Epidemiological and clinical aspects of respiratory pathologies during pregnancy and puerperality. Int $\mathbf{J}$ Reprod Contracept Obstet Gynecol 2018;7:829-34. 